\title{
Optimum Technique for Investigations of Machining Parameters in Titanium (Grade5) Alloy Turning the Use of Carbide Tip Tools
}

\author{
Sivakoteswararao Katta ${ }^{1}$, G. Chaitanya ${ }^{2}$ \\ ${ }^{1}$ Department of Mechanical Engineering, Acharya Nagarjuna University, Guntur, India \\ ${ }^{2}$ Department of Mechanical Engineering, RVR\&JC College of Engineering, Guntur, India
}

Email address:

sivakote14@gmail.com(S. Katta), chaitanyagoteti16@gmail.com(G. Chaitanya)

To cite this article:

Sivakoteswararao Katta, G. Chaitanya. Optimum Technique for Investigations of Machining Parameters in Titanium (Grade5) Alloy Turning the Use of Carbide Tip Tools. American Journal of Mechanical and Industrial Engineering. Vol. 3, No. 2, 2018, pp. 27-33.

doi: 10.11648/j.ajmie.20180302.11

Received: January 10, 2018; Accepted: May 7, 2018; Published: June 11, 2018

\begin{abstract}
Carbide inserts are utilized to enhance the execution of machining applications, for example, machining of hard materials and difficult to machining materials like titanium alloys. The surface roughness (Ra) and tool wear forecast assume a huge part of machining for a long time arranging and control of machining parameters and enhancement of cutting conditions. The present work thinks about the execution of carbide tip tools in machining of titanium (ti-6al-4v) alloys, under turning process, The impact of machining parameters, on surface finishing and cutting force has been broke down utilizing response surface methodology.DOE Software utilized for test trails diminishment, Scanning electron microscopy (SEM) pictures are utilized to watch the surface morphology and to anticipate the tool wear. It has been discovered that the machining of titanium (grade 5) alloy at lower feeds and higher speed is enhanced by utilizing carbide tip tools. Feed is the most commanding parameter on surface roughness.
\end{abstract}

Keywords: Titanium (Grade 5), RSM, DOESoftware, Surface Roughness, Cutting Force

\section{Introduction}

Machining parameters Optimization is valuable in phrases of presenting precision and effective machining. So a try is made to find optimized machining parameters the use of carbide inserts with the useful resource of the evolution of surface roughness and cutting force. Because of their higher hardness, carbide-reducing cost widely used within the production enterprise these days than alloy steels.Carbide tip tools are extensively used within the metal running enterprise and offer the first-class opportunity for maximum turning operations with low value. Anne Venugopal and popuribangaru babu et al. exploratory investigations had been carried out to collect the suitable parameters for machining titanium alloys. The impact of machining parameters, for example, feed, speed, depth of cut and again rake point on cutting energy, and surface roughness were examined. The influence of these parameters, on slicing electricity and surface roughness, has been constructed up making use of the exam of change. Vijay s, krishnarajv et al. the intention of their paintings is to boost cutting powers caused amid machining and to and to lessen the surface roughness of the machined parts. Dr. c ,j Rao et al. in their exam reviews tested the influence of the effect of speed and depth of cut on cutting power and surface roughness while operating with a device manufactured from fired substances. The consequences have proven that it's far sustaining fee which has status impact both on cutting strength and in addition surface roughness mithislesh Kumar Dikshit, as it Baran puri et al. their exploration study found that the quadratic version is first-class outfitted for forecast of the electricity segments. Suriya Sahu, B.B chowdary et al. in their exam discovered that machining of difficult to cut metals at higher speeds and decrease encourages is enhanced by means of utilizing included units .okay bhardam et al. surveyed the paper about demonstrating and improvement of EDM procedure utilizing RSM.shekel Ahmed 1, PradeepKumar m et al. proven that the method of dim social research turned into utilized to 
determine the maximum noteworthy control factors influencing the parameters . Gupta of their exam inspired an enterprise to reveal the device to put on and surface roughness thru response surface method amid tough turning of Aisi-h11steel with tin blanketed fired additions.

\section{Experimental Methods}

The present work manages the turning of difficult-to-cut, material, for example, titanium (grade 5) alloy. It is a critical designing material utilized in the assembling of segments in bio-medical and aviation ventures. Since the present work in the assembling business is dry machining, it was connected to assess the execution of uncoated instruments in a run of the mill producing processes. The explore manages to the machine of high-quality titanium (grade 5) alloy completed with uncoated carbide tip tool in CNC machine. Strong bar of titanium (grade 5) alloy, with $30 \mathrm{~mm}$ diameter and $150 \mathrm{~mm}$ long, were utilized as the workpiece. Material with a hardness of 38 HRC economically accessible uncoated carbide tips was utilized with the geometry of CNMG190612 turning methods.

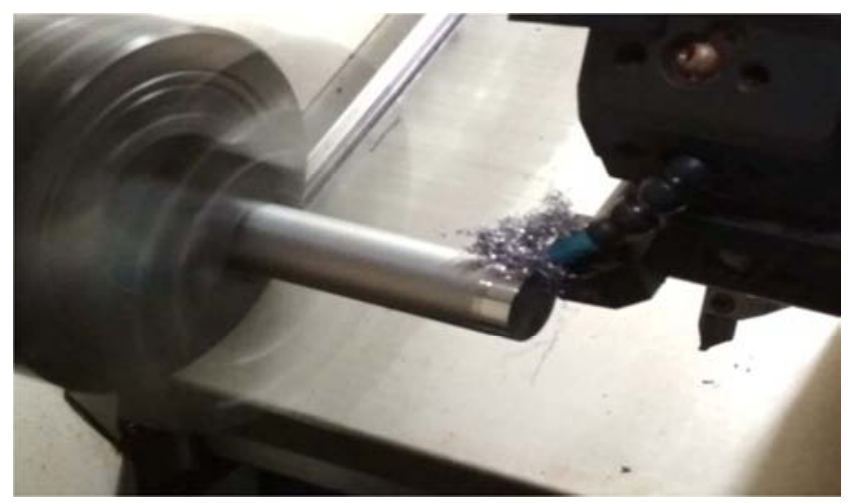

Figure 1. MachiningofTitanium (TI-6AL-4V) alloy.

Turningtestswerecompletedatthreediversecuttingcondition whichwere100,

150 , and $200 \mathrm{~m} / \mathrm{min}(\mathrm{V})$ andFeedrateswere $0.1,0.15,0.2 \mathrm{~mm} / \mathrm{rev}(\mathrm{f}$ )anddepthofcut(d)was0.4,0.6,0.8mmallthroughthe examinations.

This

littledepthofcutwasutilizedtocompletetheprocessof turning. The

cuttingconditionswerekeptconsistentwitheachoftheuncoated carbide tool stridesallthrough the examination.

\subsection{Tool Wears Measurement}

Tool wear is the maximum important aspect that affects tool life and product quality in the machining process.A series of turning experiments conducted on titanium (grade 5) alloy become completed at various cutting velocities, feed, and depth of cut. On this work photographs of device wear had been taken using SEM and an optical microscope used for measuring tool flank and crater wear, and notches on the surface of the tool after machining, SEM image analysis gives accurate values for tool wear, to, optimize machining parameters effectively while machining titanium(Grade5) alloy, with uncoated carbide tip tools.

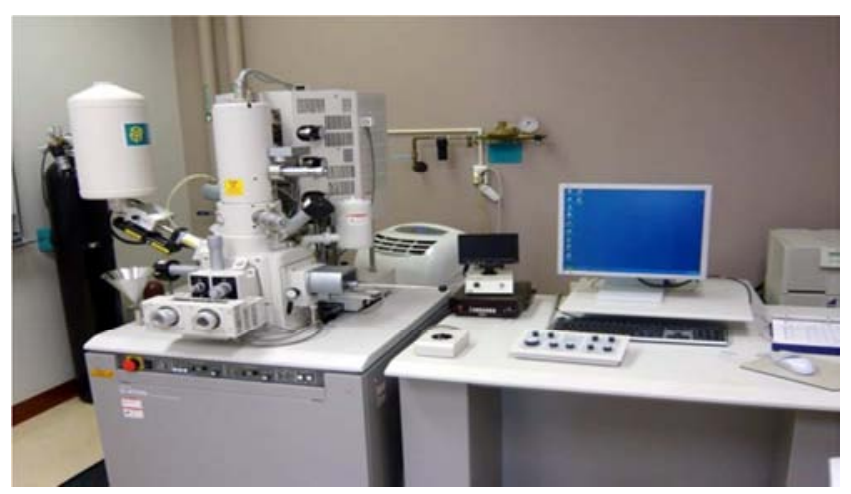

Figure 2. SEM analysis.

\subsection{Surface Roughness Measurement}

The surface roughness was estimated by utilizing taylorHobson surface roughness tester. the accompanying cutting conditions were utilized estimating surface roughness ,cutting speed (V) of $100,150,200 \mathrm{~m} / \mathrm{min}$.feed (f) of $0.1,0.15,0.2 \mathrm{~mm} / \mathrm{rev}$ and depth of cut (D) $0.4,0.6,0.8 \mathrm{~mm}$.

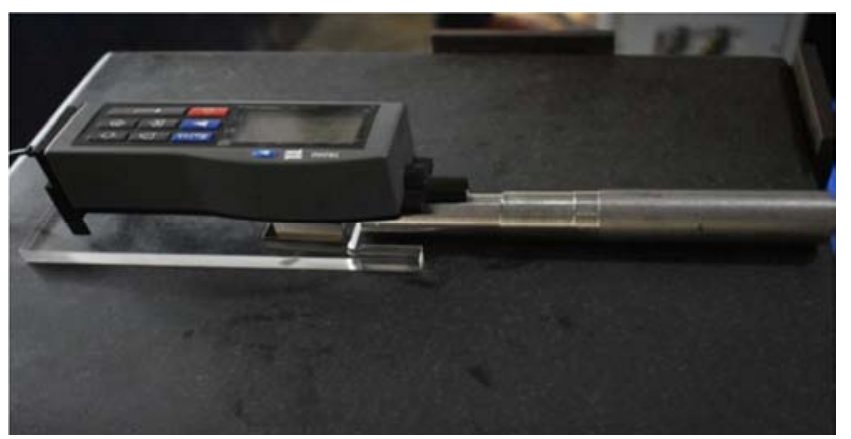

Figure 3. Surface roughness measurement.

\subsection{Design of Experiments}

The important stage in the design experiments using response surface methodology (RSM) is the selection of design factors to optimize the process parameters to achieve the best quality performance of the powerful statistical. It is tool and analysis for experiments adopted to optimize the design used in the application of design parameter, effectively to produce high - quality product at a relatively low cost with RSM. It is an approach to analyze the software if the numbers of process parameters carried out using the design of software of experiments have to be conducted to get the optimized parameter. To make the task easy, RSM uses the design of BBD model to study the process parameter with a small number of experiments. The prevailing experimental investigation deals with the layout of the test through the RSM methodology with a BBD to decide the significance of the factors or the parameters. Seventeen experiments with an aggregate of different cutting parameters are randomly repeated. Three levels of cutting speeds, feed rates and depth of cuts are tested. 
Table 1. Process parameters.

\begin{tabular}{lllll}
\hline SI.No & Cuttingparameters & Level1 & Level2 & Level3 \\
\hline 1 & Cuttingspeed(m/min) & 100 & 150 & 200 \\
2 & Feed(mm/rev) & 0.1 & 0.15 & 0.2 \\
3 & Depthofcut $(\mathrm{mm})$ & 0.4 & 0.6 & 0.8 \\
\hline
\end{tabular}

\subsection{Experimental Plan}

Table 2. Design layout.

\begin{tabular}{|c|c|c|c|c|c|}
\hline Run & Speed(m/min) & Feed(mm/re) & Depth of cut(mm) & $\operatorname{Surfaceroughness}(\mu)$ & Cuttingforce(N) \\
\hline 1 & 200 & 0.15 & 0.8 & 0.81 & 172 \\
\hline 2 & 150 & 0.15 & 0.6 & 0.76 & 132 \\
\hline 3 & 100 & 0.15 & 0.4 & 0.6 & 82 \\
\hline 4 & 150 & 0.2 & 0.4 & 0.83 & 168 \\
\hline 5 & 150 & 0.1 & 0.4 & 0.65 & 97 \\
\hline 6 & 150 & 0.15 & 0.6 & 0.74 & 128 \\
\hline 8 & 200 & 0.1 & 0.6 & 0.53 & 122 \\
\hline 9 & 150 & 0.15 & 0.6 & 0.72 & 129 \\
\hline 10 & 200 & 0.15 & 0.4 & 0.79 & 152 \\
\hline 11 & 150 & 0.15 & 0.6 & 0.75 & 122 \\
\hline 12 & 150 & 0.2 & 0.8 & 0.87 & 159 \\
\hline 13 & 100 & 0.1 & 0.6 & 0.49 & 76 \\
\hline 14 & 100 & 0.2 & 0.6 & 0.61 & 98 \\
\hline 15 & 150 & 0.1 & 0.8 & 0.67 & 92 \\
\hline 16 & 150 & 0.15 & 0.6 & 0.75 & 129 \\
\hline 17 & 100 & 0.15 & 0.8 & 0.55 & 103 \\
\hline
\end{tabular}

Table 3. Annovafor surface roughness.

\begin{tabular}{|c|c|c|c|c|c|c|}
\hline Soure & Sum of Squares & df & Mean Square & FValue & p-valueProb $>$ F & \\
\hline Model & 0.078 & 9 & $8.634 \mathrm{E}-003$ & 24.8 & 0.0002 & Significant \\
\hline A-speed & $6.801 \mathrm{E}-003$ & 1 & $6.801 \mathrm{E}-003$ & 19.5 & 0.0031 & \\
\hline B-feed & $5.706 \mathrm{E}-004$ & 1 & $5.706 \mathrm{E}-004$ & 1.64 & 0.2411 & \\
\hline C-depth of cut & $2.542 \mathrm{E}-003$ & 1 & $2.542 \mathrm{E}-003$ & 7.31 & 0.0305 & \\
\hline $\mathrm{AB}$ & $3.188 \mathrm{E}-003$ & 1 & $3.188 \mathrm{E}-003$ & 9.16 & 0.0192 & \\
\hline $\mathrm{AC}$ & $4.875 \mathrm{E}-004$ & 1 & $4.875 \mathrm{E}-004$ & 1.40 & 0.2751 & \\
\hline $\mathrm{BC}$ & $2.202 \mathrm{E}-005$ & 1 & $2.202 \mathrm{E}-005$ & 0.063 & 0.8086 & \\
\hline$A^{2}$ & 0.015 & 1 & 0.015 & 44.05 & 0.0003 & \\
\hline $\mathrm{B}^{2}$ & $1.592 \mathrm{E}-003$ & 1 & $1.592 \mathrm{E}-003$ & 4.58 & 0.0697 & \\
\hline $\mathrm{C}^{2}$ & $2.438 \mathrm{E}-003$ & 1 & $2.438 \mathrm{E}-003$ & 7.01 & 0.0331 & \\
\hline Residual & $2.435 \mathrm{E}-003$ & 7 & $3.479 \mathrm{E}-004$ & & & \\
\hline Lack of Fit & $2.124 \mathrm{E}-003$ & 3 & 7.079E-004 & 9.10 & 0.0293 & Significant \\
\hline Pure Error & $3.113 \mathrm{E}-004$ & 4 & $7.783 \mathrm{E}-005$ & & & \\
\hline Cor Total & 0.080 & 16 & & & & \\
\hline
\end{tabular}

The Model F-estimation of 24.82 infers that the model is significant. There is just a $0.02 \%$ possibility that an F-esteem this expansive could happen because of noise. Estimations of "Prob > F" under 0.0500 demonstrate show terms are significant. The "lack of Fit F-esteem" of 9.10 infers the Lack of Fit is significant. There is just a2.93\% chance that a "lack of Fit F-esteem" this significant could happen because of noise. The "Pred R-Squared" of 0.5699 isn't as near the "Adj R-Squared" of 0.9305 as one may regularly anticipate.

Final equation in terms of actual factors:

$$
\begin{array}{r}
\sqrt{\mathrm{Ra}}=0.38030+0.005986 \text { speed }+1.73406 \text { feed } 0.91508 \mathrm{doc}+0.011292 \text { speed } * \text { feed }+0.00103 \mathrm{speed} * \text { doc }+0.2346 \text { feed } * \\
\text { doc0.0000241speed } 2-7.77881 \text { feed } 2+0.6016 \mathrm{doc} 2
\end{array}
$$


Table 4. Annovafor cutting force.

\begin{tabular}{lllllll}
\hline Source & SumofSquares & df & MeanSquare & FValue & p-valueProb>F & Significant \\
\hline Model & 29.97 & 3 & 9.99 & 44.87 & $<0.0001$ & \\
A-speed & 18.14 & 1 & 18.14 & 81.48 & $<0.0001$ & \\
B-feed & 11.63 & 1 & 11.63 & 52.24 & 0.0001 & \\
C-depthOfcut & 0.20 & 1 & 0.20 & 0.91 & 0.3585 & \\
Residual & 2.89 & 13 & 0.22 & & & Significant \\
LackofFit & 2.79 & 9 & 0.31 & 11.62 & & \\
PureError & 0.11 & 4 & 0.027 & & & \\
CorTotal & 32.87 & 16 & & & & \\
\hline
\end{tabular}

Estimations of "Prob> F" under 0.0500 demonstrate show terms are significant. For this situation cutting speed, the feed rate is critical model terms. The "Pred R-Squared" of 0.8235 is insensible concurrence with the "Adj R-Squared" of 0.8916.

Final equation in terms of actual factors:

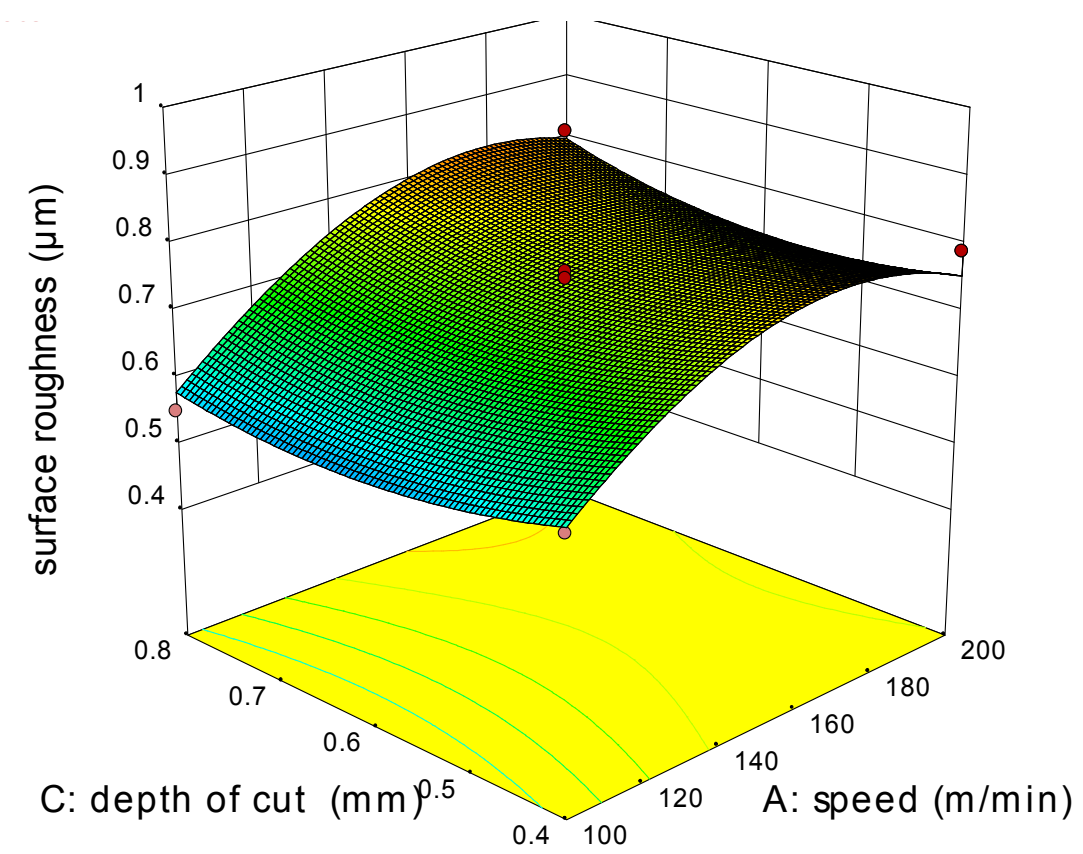

Figure 4. Surface graphs for Ra\&Fc data.

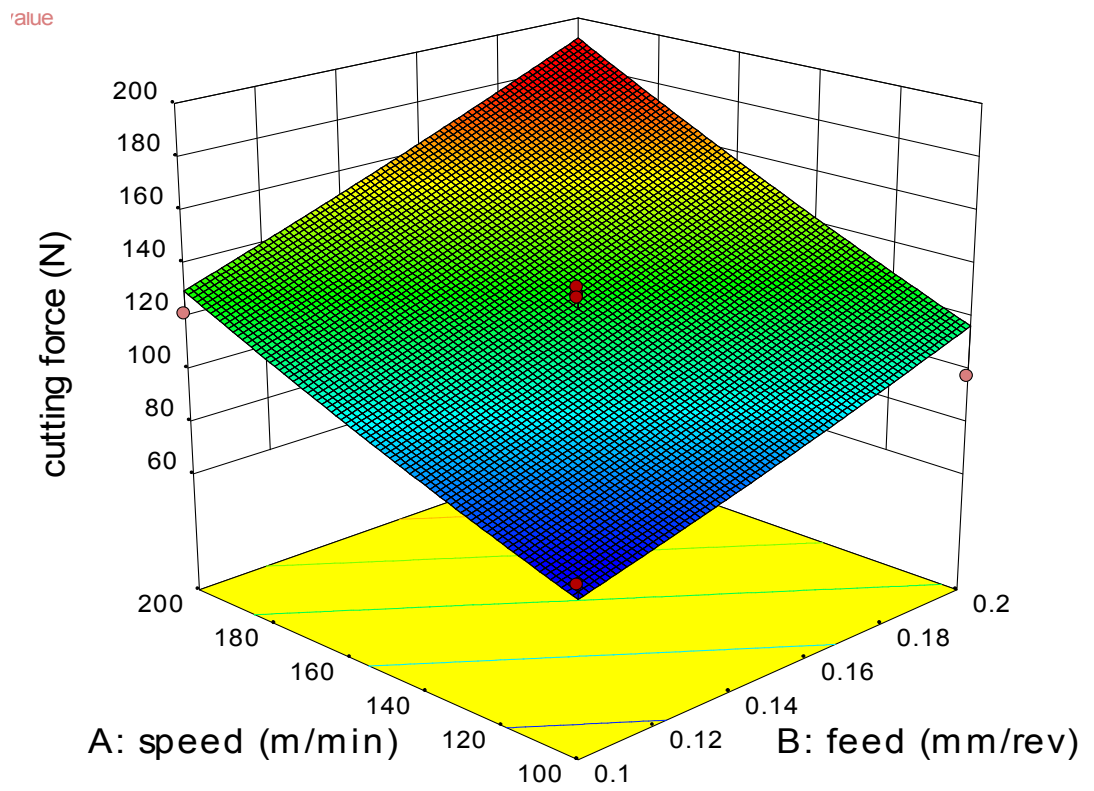

Figure 5. Surface graphs for Ra\&Fc data. 


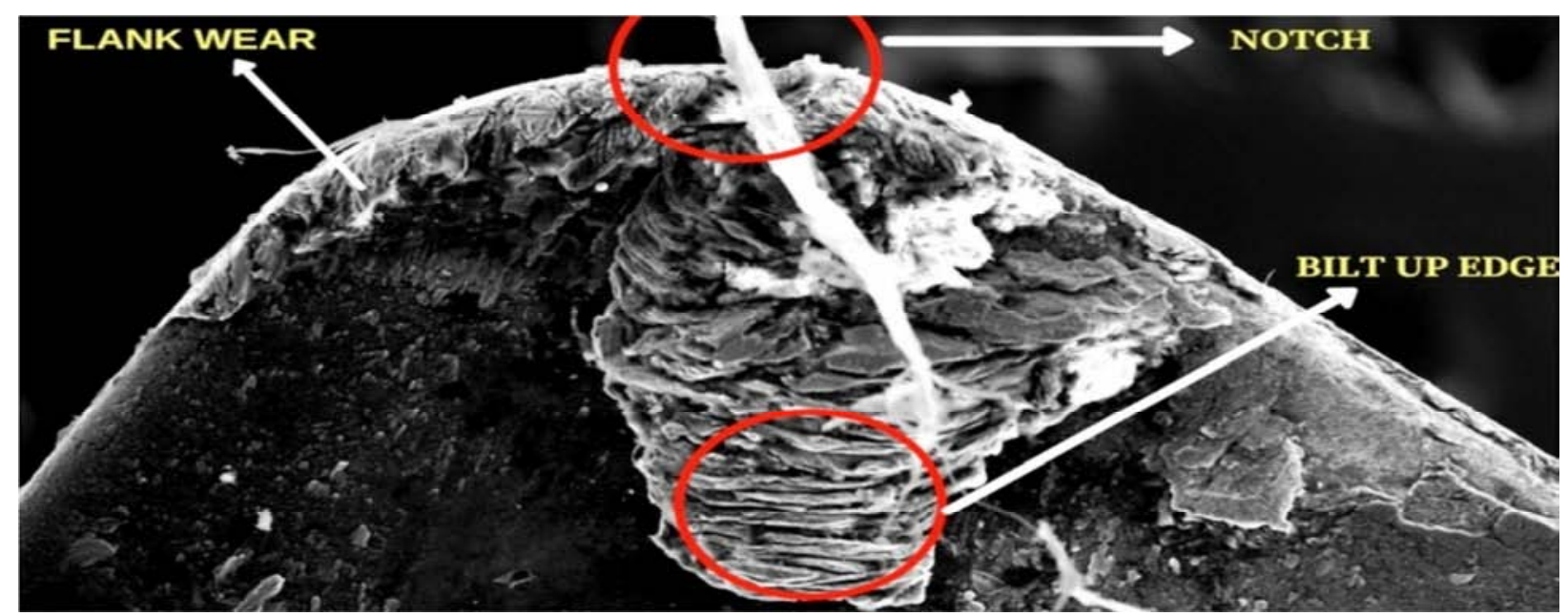

Figure 6. SEM image for tool wear.
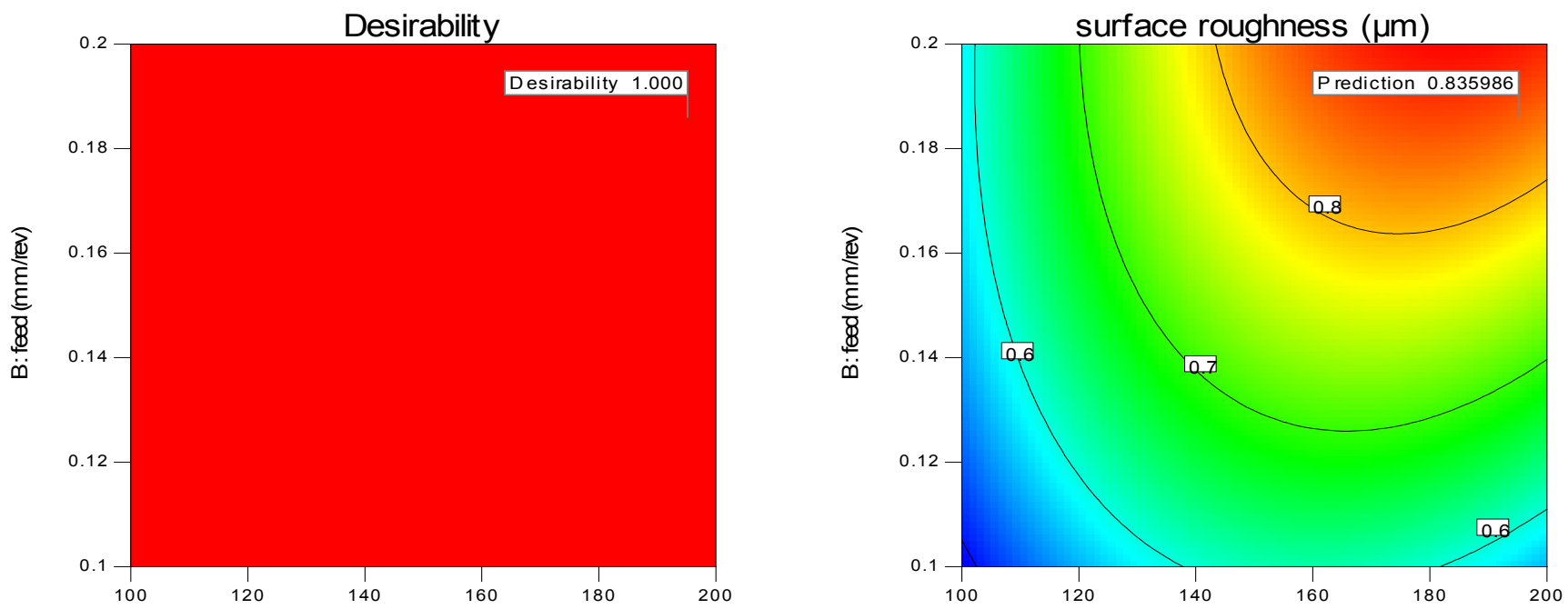

A: speed ( $\mathrm{m} / \mathrm{min})$

A: speed ( $\mathrm{m} / \mathrm{min})$

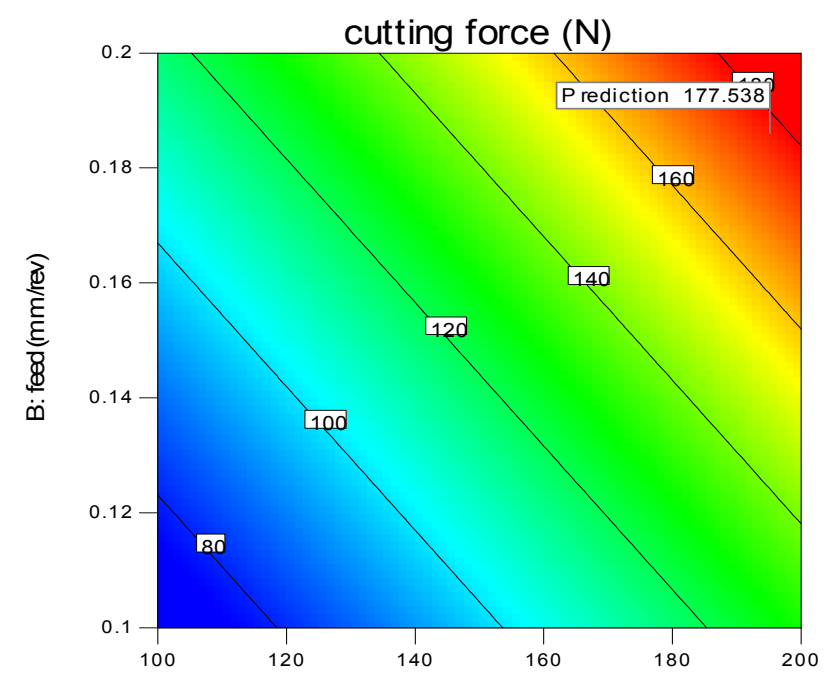

A: speed $(\mathrm{m} / \mathrm{min})$

Figure 7. Surface graphs for Ra \& FC data desirability. 


\section{Results and Discussions}

These results concluded that the carbide tool produces better Ra with admire to excessive velocity and low feedrate, but the depth of cut has minimum impact on surface roughness. The aggregate of low feed rate and immoderate cutting velocity is necessary for minimizing the surface roughness. If feed rate is altered, it'll have an essential impact on the surface roughness. From the response surface technique, it's been placed that the feed plays as a top parameter for decreasing surface roughness, whereas the intensity of reducing is having the least effective or does now not have widespread effect at the surface roughness. Microscopic assessment of the worn surfaces on the lowering speed showed no enormous put on of the reducing damage due to dry surroundings. Abrasion was the primary wear mechanism located at all the reducing conditions. The intensity of reducing has a big effect on the damage rate. The widespread decrease in device behavior foruncoated carbide tool at the better intensity of cut can be attributed to the temperature rise. Results show that the machining of tough work materials at higher speeds is advanced via using carbide tools. From the experimental research, it is located that uncoated carbide tools provide higher consequences with the dry environment with optimized machining parameters.It's far low fee machining as compared to other machining techniques, environmentalpleasant greatly reduces machining cost.

Table 5. ConfirmationReport.

\begin{tabular}{llll}
\hline \multicolumn{4}{l}{ Confirmation Report: predicted/actual } \\
\hline $\mathrm{A}$ & Speed & 195.19 & 200 \\
$\mathrm{~B}$ & feed & 0.19 & 0.2 \\
$\mathrm{C}$ & Depthofcut & 0.54 & 0.8 \\
$\mathrm{Ra}$ & Surface roughness & 0.83 & 0.87 \\
$\mathrm{Fc}$ & Cutting force & 177.538 & 179 \\
\hline
\end{tabular}

\section{Conclusion}

This results concluded that the carbide tool produces better Ra with admire to excessive velocity and low feedrate, but the depth of cut has minimum impact on surface roughness. The aggregate of low feed rate and immoderate cutting velocity is necessary for minimizing the surface roughness. If feed rate is altered, it'll have an essential impact on the surface roughness. From the response surface technique, it's been placed that the feed plays as a top parameter for decreasing surface roughness, whereas the intensity of reducing is having the least effective or does now not have widespread effect at the surface roughness. Microscopic assessment of the worn surfaces on the lowering speed showed no enormous put on of the reducing damage due to dry surroundings. Abrasion was the primary wear mechanism located at all the reducing conditions. The intensity of reducing has a big effect on the damage rate. The widespread decrease in device behavior foruncoated carbide tool at the better intensity of cut can be attributed to the temperature
rise.Results show that the machining of tough work materials at higher speeds is advanced via using carbide tools. From the experimental research, it is located that uncoated carbide tools provide higher consequences with the dry environment with optimized machining parameters.It's far low fee machining as compared to other machining techniques, environmentalpleasant greatly reduces machining cost.

\section{References}

[1] Dr. c. j. rao, Dr. D. nagaswaramRao B, P. Srihari, the influence of cutting parameters on cutting force and surface finish in turning operation, process engineering64(2013)1405-1415.

[2] J.A. Ghani, I.A. Choudhury, H.H. Masjuki. Wear mechanism of TiN coated carbide and uncoated cermets tools at high cutting speed applications, Journal of Materials Processing Technology 153-154 (2004) 1067-10734.

[3] Tugrul O” zel Tsu-Kong Hsu · Erol Zeren, "Effects of cutting edge geometry, workpiece hardness, feed rate and cutting speed on surface roughness and forces in finish turning of hardened AISI H13 steel", Int J Adv Manuf Technol (2005) 25: $262-269$

[4] Abhijeet S. Morea, Wenping Jiang, W.D. Brown, Ajay P. Malshe a, Tool wear and machining performance of cBN-TiN coated carbide inserts and PCBN compact inserts in turning AISI 4340 hardened steel, Journal of Materials Processing Technology 180 (2006) 253-262.

[5] Ibrahim Ciftci, Machining of austenitic stainless steels using CVD multi-layer coated cemented carbide tools, Tribology International 39 (2006) 565-569.

[6] Reginaldo T. Coelho, Eu-Gene Ng, M.A. Elbestawi, Tool wear when turning hardened AISI 4340 with coated PCBN tools using finishing cutting conditions, International Journal of Machine Tools \& Manufacture 47 (2007) 263-272.

[7] D.I. Lalwani, N.K. Mehta, P.K. Jain, Experimental investigations of cutting parameters influence on cutting forces and surface roughness in finish hard turning of MDN250 steel, Journal of materials processing technology 206 (2008) 167-179.

[8] Tugrul O zel, Tsu-KongHsu, Erol Zeren, The experimental investigation of the effects of uncoated, PVD- and CVDcoated cemented carbide inserts and cutting parameters on surface roughness in $\mathrm{CNC}$ turning and its prediction using artificial neural networks, Robotics and Computer-Integrated Manufacturing 25 (2009) 211-223.

[9] Abhay Bhatt, Helmi Attia,R.Vargas, V.Thomson, Wear mechanisms of WC coated and uncoated tools in finish turning of Inconel 718, Tribology International 43 (2010) 1113-1121.

[10] M.A. Eliakim, M.D.Abad, M.M.Abdelhameed, M.A.Shalaby, S.C.Veldhuis, Wear behavior of some cutting tool materials in hard turning of HSS, Tribology International 44 (2011) 11741181 .

[11] Jan C. Aurich, Tina Eyrisch and Marco Zimmermann, Effect of the coating system on the tool performance when turning heat treated AISI 4140, Procedia CIRP 1 (2012) 214-219. 
[12] CLVRS V Prasad, S V Ramana, P L Pavani, K Ramji, Experimental Investigations for the Prediction of Wear Zones on the Rake Face of Tungsten Carbide Inserts Under dry Machining Conditions, Procedia CIRP 8 (2013) 528-533.

[13] Alain Kusmoko and Alan Crosky, Wear Mode Map Evaluation of Induction Hardened 4140 and Carburized $8617 \mathrm{H}$ Steels on 1040 Steel, Advanced Materials Manufacturing \& Characterization Vol 3 Issue 2 (2013).

[14] Dipti Kanta Das, Ashok Kumar Sahoo, Ratnakar Das, B. C. Routara, Investigations on hard turning using coated carbide insert: Grey based Taguchi and regression methodology, Procedia Materials Science 6 (2014) 1351-1358.

[15] Mithilesh Kumar Dikshita, Asit Baran Puria, Atanu Maybe, Experimental Study of Cutting Forces in Ball End Milling of Al2014-T6 Using Response Surface Methodology, Procedia Materials Science6(2014) 612-622.

[16] SupriyaSahua B.B.Choudhuryb, Optimization of Surface Roughness using Taguchi Methodology \& Prediction of Tool Wear in Hard Turning Tools, Materials Today: Proceedings2(2015)2615-2623.
[17] Manish Gangil,M. K Pradhan, modeling and optimization of electric discharge machining g process using RSM Materials Today: Proceedings 4 (2017) 1752-1761.

[18] Shakeel Ahmed 1, PradeepKumar m, optimization of reaming process parameters for titanium ti-6al-4v alloy using grey relational analysis, November 11-17, 2016.

[19] J S Dureja,V K Gupta,V S Sharma, and M Dogra, Design optimization of cutting conditions and analysis of their effect on tool wear and surface roughness during hard turning of AISI-H11 steel with a coated-mixed ceramic tool, Proc. IMechE Vol. 223.

[20] Kosaraju Satyanarayana, Anne Venu Gopal and Popuri Bangaru Babu, Analysis for optimal decisions on turning Ti6Al-4V with Taguchi-grey method, J Mechanical Engineering Science 2014, Vol 228(1) 152-157! IMechE 2013. 